http://jmscr.igmpublication.org/home/ ISSN (e)-2347-176x ISSN (p) 2455-0450

crossref DOI: https://dx.doi.org/10.18535/jmscr/v8i2.63

Journal Of Medical Science And Clinical Research

IGM Publication

An Official Publication of IGM Publication

\title{
A Cross Sectonal Observational Study of Prognostic Value of Veno-Arterial Carbon Dioxide Difference in Septic Shock Patients in ICU
}

\author{
Authors \\ Dr Kambhampati S L N Sunanda Kameswari ${ }^{1}$, \\ Dr A.Satyanarayana' $\mathrm{MD}^{2}$, Professor and HOD
}

\begin{abstract}
Background and Aim: Early identification of tissue hypoperfusion helps in decreasing mortality due to septic shock. This tissue hypoperfusion not only occurs due to decreased perfusion pressures due to hypotension, caused by reduced cardiac output (CO), but also due to the abnormal regional distribution of blood flow.Metabolic variables like central venous oxygen saturation(scvo2), serum lactate are established markers of tissue hypoperfusion. Recently, the central venous-to-arterial carbon dioxide difference ( $v$ a)CO2 has been proposed as an alternative marker of tissue hypoperfusion. So we deigned this study aiming to know the porognostic value of venous-to-arterial carbon dioxide difference in septic shock.

Materials and Methods: Patients, admitted in ICU, satisfying the criteria of septic shock were studied. Arterial blood gas,central venous samples are obtained, on admission ,6h,12h,24h.sixty patients were studied.Patients were classified into survivors and nonsurvivors. venous-to-arterial carbon dioxide difference difference and serum were evaluated and correlated to outcome.

Results: The mean Veno-arterial carbon dioxide difference in Survivors at the time of admission (T0), 6 hours after admission (T6), 12 hours after admission (T12), 24 hours after admission (T24), was 7.23+1.41, $5.8+0.87,5.71+0.80,5.52+0.82 \mathrm{mmHg}$ respectively and in Non-survivors was $8.51+1.31,9.4+0.88$, $9.84+1.01,9.78+0.78 \mathrm{mmHg}$ respectively with a statistically significant difference between survivors and Non-survivors $(P<0.05)$. The mean serum lactate in Survivors at the T0, T6, T12, T24 was 7.74+1.54, $5.70+1.29,3.9+1.18,2.45+1.09 \mathrm{mmol} / \mathrm{l}$ respectively and in Non-survivors was 8.69+2.08, 9.09+1.58, $8.94+1.34,8.79+1.33 \mathrm{mmol} / \mathrm{l}$ respectively. There was no significant statistical difference at the time of admission $T 0(p>0.05)$, and a statistically significant difference was observed at T6, T12, T24( $p<0.05)$. The lactate clearance at the end of Ghours in survivors and non-survivors was $26 \%$ and $11 \%$, and at the end of 24 hours was $68 \%$ and $16 \%$, respectively. A positive correlation between veno-arterial carbon dioxide difference and serum lactate was also observed at T0,T6, T12, T24.

Conclusion: veno-arterial carbon dioxide difference can be used as markers of prognosis in septic shock and it has a positive correlation with serum lactate.
\end{abstract}

\section{Introduction}

Sepsis is a dysregulated host response to infection, causing life-threatening organ dysfunction. Septic shock is a subset of sepsis with circulatory and cellular/metabolic dysfunction associated with a higher risk of mortality ${ }^{1}$.
Multiorgan dysfunction syndrome, which leads to poor outcomes in septic shock is due to global tissue hypoperfusion. Therefore early identification of tissue hypoperfusion and treatment helps in decreasing morbidity and mortality due to septic shock ${ }^{2}$. 
This tissue hypoperfusion not only occurs due to hypotension caused by reduced cardiac output $(\mathrm{CO})$ that leads to reduced global oxygen delivery (DO2) but also due to the abnormal regional distribution of blood flow $^{3}$. So hemodynamic support should consider both global and regional perfusion as well as end-organ function ${ }^{4}$.

Several clinical studies have demonstrated that persistent impairment of perfusion-related physiological variables is associated with increased mortality in septic shock patients ${ }^{5,6,7}$ and current guidelines of hemodynamic management of severe sepsis and septic shock also recommend the use of these global markers of tissue hypoxia like central venous oxygen saturation and serum lactate clearance as resuscitation endpoints ${ }^{8,9}$.

Recently, the central venous-to-arterial carbon dioxide difference ( $\mathrm{v}-\mathrm{a}) \mathrm{CO}_{2}$ has been proposed as an alternative marker of tissue hypoperfusion and has been used to guide treatment for shock. Persistently, high $\mathrm{v}-\mathrm{aCO}_{2}$ predicts adverse clinical outcomes independently of oxygen-derived parameters like serum lactate and central venous oxygen saturation and it could anticipate lactate variations ${ }^{10}$.

On this background we tried to evaluate the prognostic value of veno-arterial carbon dioxide difference and and its relationship with the lactate variations in septic shock patients in ICU.

\section{Aims And Objectives}

1. To asses the relationship between venoarterial carbon dioxide difference measured at different time intervals (at the time of admission (T0), 6hours, 12hours, and 24 hours post-enrollment) and outcome in septic shock patients in terms of mortality.

2. To study the relationship between veno arterial carbon dioxide difference and serum lactate in septic shock patients measured over 24 hours.
Materials and Methods

- Design:cross-sectional observational study

- Study Period:23 months(September 2017 to August 2019)

- Setting:Intensive Care Unit (ICU) in a tertiary care hospital.

- Study Population And Size: All patients admitted to ICU with septic shock satisfying the inclusion criteria during the study period $(n=82)$.

\section{Inclusion Criteria}

Adult patients ( $>18$ years) satisfying the criteria of septic shock (persisisting hypotension requiring vasopressor supportto maintain $\mathrm{MAP}>65 \mathrm{mmHg}$ or lactate $>2 \mathrm{mmol} / \mathrm{lL}$ despit adequate fluid resuscitation) were included.

\section{Exclusion Criteria}

Pregnancy, Do not resuscitate status, Readmission to ICU within a single hospital stay, Absence of internal jugular or subclavian central venous access, Patients who denied consent or who survived $<24$ hours, Patients with other etiologies of shock discovered during their ICU stay(cardiogenic,hypovolemic,obstructive shock), patients with chronic COPD and Asthma, patients with Chronic liver disease.

\section{Methodology}

In all included patients simultaneous arterial and venous blood gas analysis were carried out up on enrollment (T0) and at 6hrs (T6),24 hrs(T24) postenrolment. All assessments were done within $1-2 \mathrm{hrs}$ of specified time. The partial pressure of carbondioxide ,serum lactate,were recorded from the central venous and arterial blood samples. Additional tests for the evaluation of shocks such as complete blood counts, electrolytes, liver and renal function tests, electrocardiogram and appropriate cultures will be done as clinical situation warranted. All patients were treated according to surviving sepsis guidelines 2016 .

Patients were followed up until death or hospital discharge over 28 days. According to the outcome, the patients were divided into two groups, Survivors and Non-survivors. The serum 
lactate, veno-arterial carbon dioxide difference were correlated with the outcome of the septic shock patients. The relationship between veno arterial carbon dioxide difference and serum lactate was also assessed.

\section{Statistical Analysis}

Data was entered in Microsoft MS Excel and analysis was done in MS Excel and MEDCALC software on a personal computer. Categorical data will be expressed in proportions and quantitative data by means and standard deviation. A p-value of 0.05 was taken as the level of significance.

\section{Observations and Results}

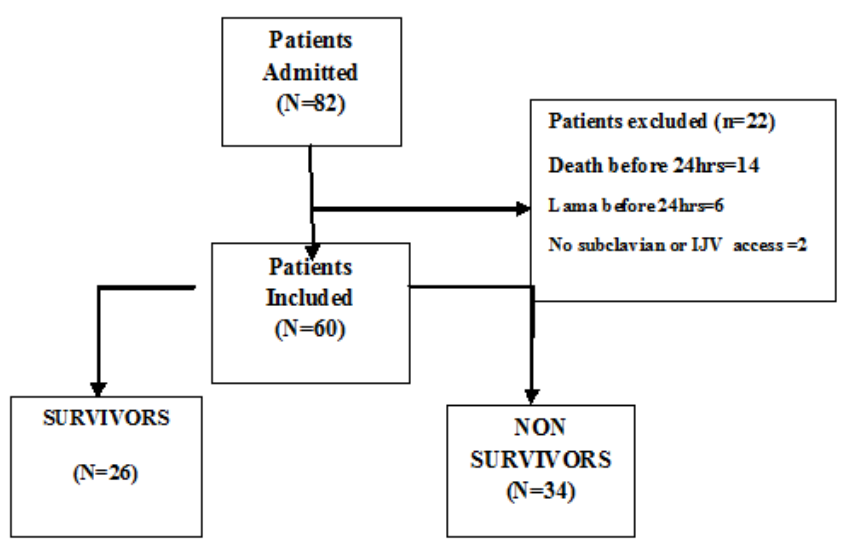

\section{Demographic Data}

The mean age in survivors was $45.96+13.46$ years, and in Non-survivors was $46.67 \pm 15.45$ years and is comparable ( $\mathrm{p}$-value $>0.05$ ).

In survivor group, $69 \%$ of the patients were males, and $32 \%$ of the patients were females. In Nonsurvivor group, $53 \%$ of the patients were males, and $37 \%$ of the patients were females with a p- value $>0.05$, showing no significant difference between the groups.

Most common etiology of septic shock was Postoperative Abdominal Surgeries- 46 patients (57\%) followed by Abdominal Sepsis- 18 patients (23\%), Lower Respiratory Tract Infections- 12 patients (15\%), Burns- 4 patients (4\%), Meningitis- 2 patients (1\%).

Figure 1 Table 1: Showing Patterns of veno-arterial carbon dioxide difference in survivors and nonsurvivors at different time intervals (T0, T6, T12, T24) in survivor group and non-survivor group.

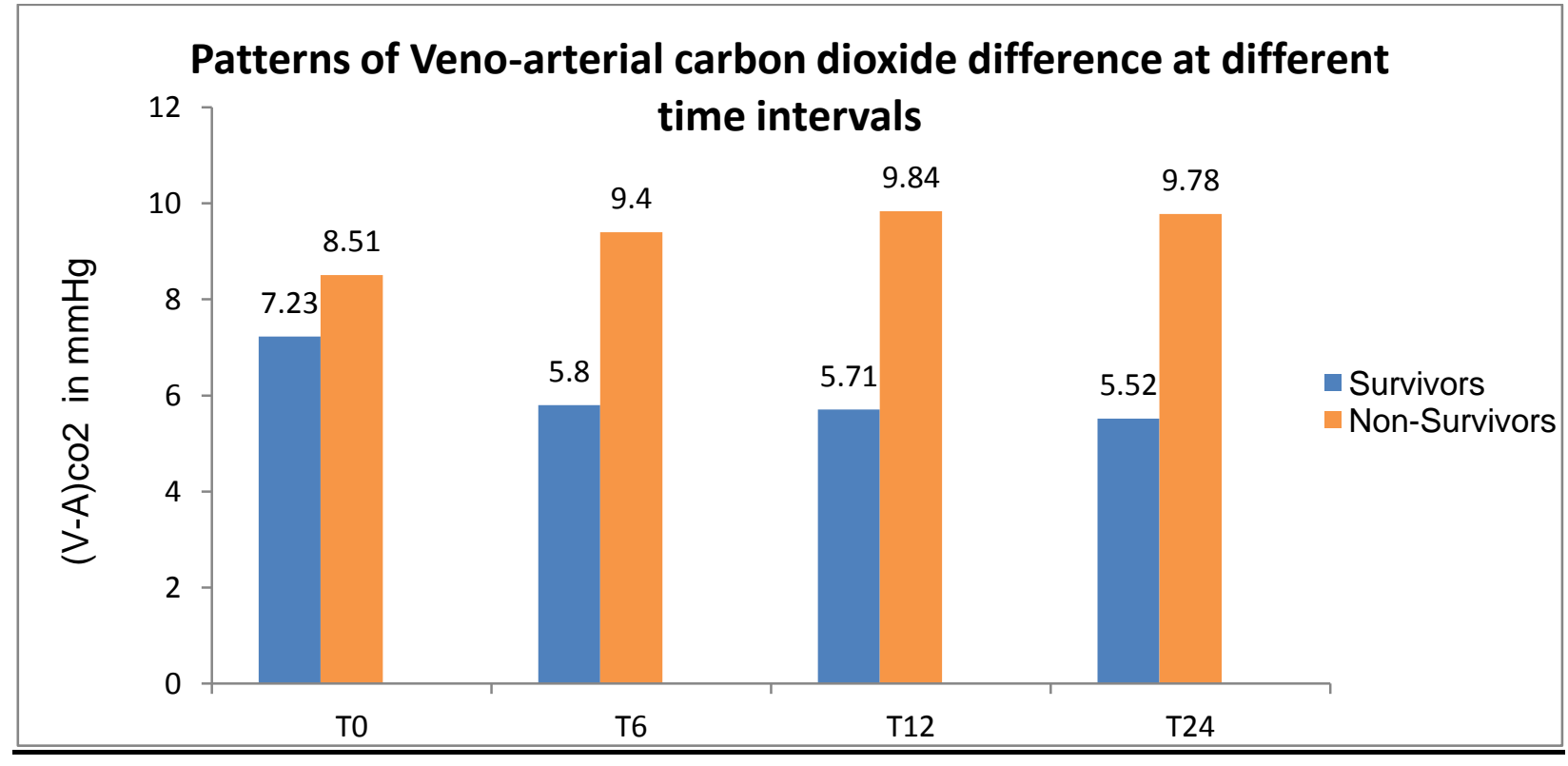




\begin{tabular}{|c|c|c|c|c|}
\hline $\begin{array}{c}\text { Venoarterialcarbondioxide difference } \\
\text { (in mmHg) at different time intervals }\end{array}$ & $\begin{array}{c}\text { Survivors } \\
(\mathbf{n = 2 6 )} \\
\text { Mean+/-SD }\end{array}$ & $\begin{array}{c}\text { Non } \\
\text { Survivors(n=34) } \\
\text { Mean }+/ \text { - SD }\end{array}$ & 'p' value & Significance \\
\hline At the time of admission(T0) & $7.23 \pm 1.41$ & $8.51 \pm 1.31$ & $0.0002^{* * *}$ & Significant \\
\hline 6hrs after admission(T6) & $5.8 \pm 0.87$ & $9.4 \pm 0.88$ & $<0.0001 * * *$ & Significant \\
\hline 12hrs after admission(T12) & $5.71 \pm 0.80$ & $9.84 \pm 1.01$ & $<0.0001 * * *$ & Significant \\
\hline 24hrs after admission(T24) & $5.52 \pm 0.82$ & $9.78 \pm 0.78$ & $<0.0001 * * *$ & Significant \\
\hline
\end{tabular}

Figure 2,3,4,5: showing sensitivity and specificity of initial veno-arterial carbondioxide measured at T0,T6.

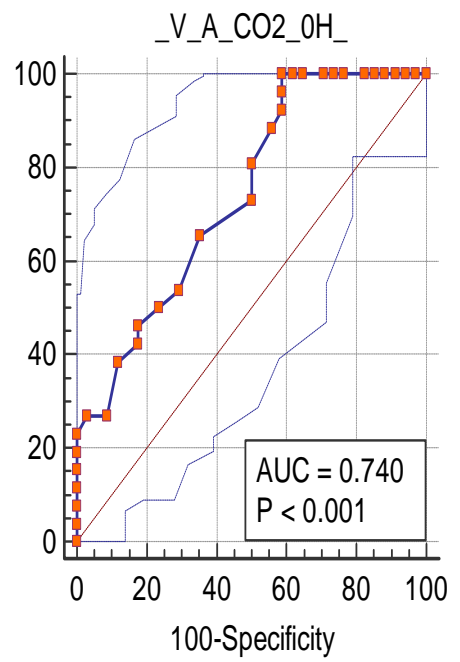

_.

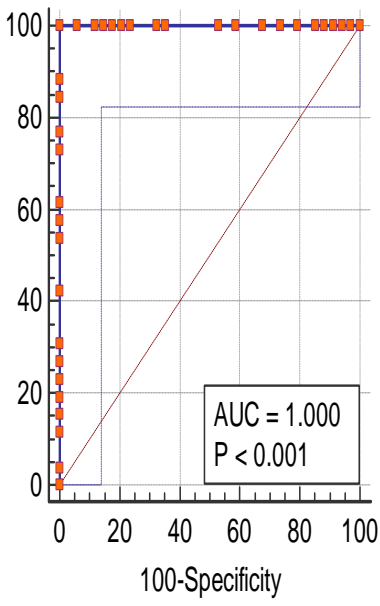

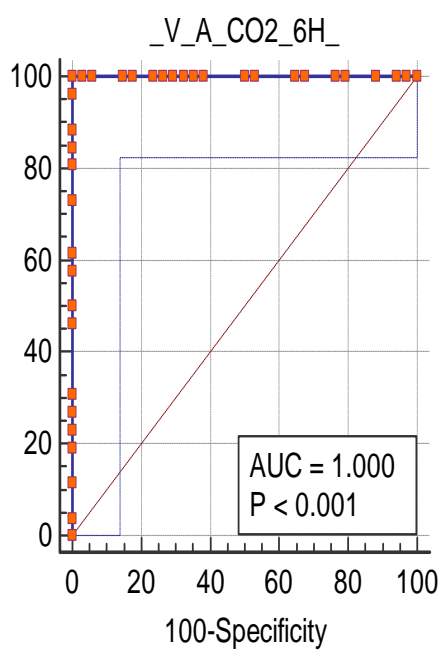

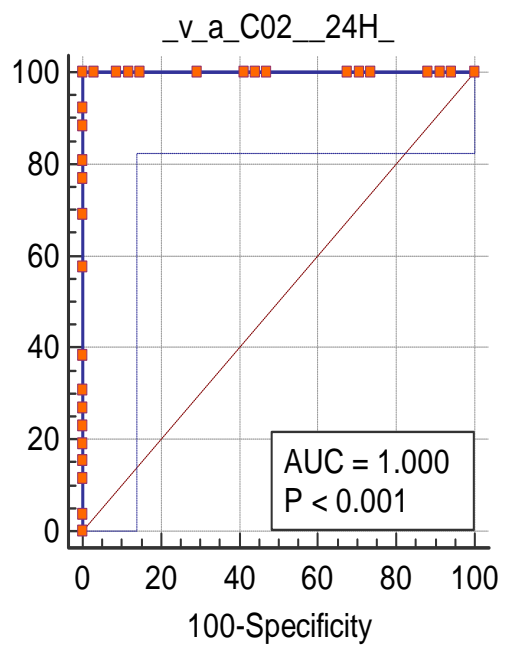

At T0, ROC of veno-arterial carbon dioxide difference shows AUC of 0.74 which shows that initial veno-arterial carbon dioxide difference is a good predictor of outcome in septic shock patients with a sensitivity of $100 \%$ and though the specificity is low $41.18 \%$.
At T6, T12, T24 ROC of veno-arterial carbon dioxide difference shows AUC of 1.00which shows that veno-arterial carbon dioxide difference at 6hours is a good predictor of outcome in septic shock patients with a sensitivity of $100 \%$ and specificity of $100 \%$ 
Table 2: Showing Patterns of serum lactate in survivor group and non-survivor group at different time intervals (T0, T6, T12, T24).

\begin{tabular}{|l|c|c|c|c|}
\hline $\begin{array}{l}\text { Lactate } \\
\text { (in mmol/l) at different time } \\
\text { intervals }\end{array}$ & $\begin{array}{c}\text { Survivors } \\
(\mathbf{n = 2 6}) \\
\text { Mean }(+/-) \text { SD }\end{array}$ & $\begin{array}{c}\text { Non-Survivors } \\
(\mathbf{n = 3 4 )} \\
\text { Mean }(+/-) \text { SD }\end{array}$ & $\begin{array}{c}\text { 'p' } \\
\text { Value }\end{array}$ & Significance \\
\hline At the time of admission(T0) & $7.74 \pm 1.54$ & $8.69 \pm 2.08$ & $\mathrm{P}=0.055$ & Not significant \\
\hline After 6hrs (T6) & $5.70 \pm 1.29$ & $9.09 \pm 1.58$ & $<0.0001^{* * * *}$ & High \\
\hline After 12hrs (T12) & $3.9 \pm 0.99$ & $68.94 \pm 1.34$ & $<0.001^{* *}$ & Significant \\
\hline Fter 24hrs (T24) & $2.45 \pm 1.09$ & $8.79 \pm 1.33$ & $<0.001^{* *}$ & Significant \\
\hline
\end{tabular}

Table 3: Serum lactate clearance at T6 in survivor and non-survivor group

\begin{tabular}{|l|c|c|c|c|}
\hline & $\begin{array}{c}\text { SURVIVORS } \\
(\mathbf{n = 2 6}) \\
\text { Mean +/- SD }\end{array}$ & $\begin{array}{c}\text { NON SURVIVORS } \\
(\mathbf{n = 3 4 )} \\
\text { Mean +/- SD }\end{array}$ & $\begin{array}{c}\text { 'p' } \\
\text { Value }\end{array}$ & Significance \\
\hline $\begin{array}{l}\text { Serum lactate clearnce(in mmol/l) at the } \\
\text { end of 6hrs. }\end{array}$ & $2.03+1.00$ & $-0.39+1.9$ & $<0.001^{* *}$ & High \\
\hline \% of lactate clearance at the end of 6hrs. & $26 \%$ & $11 \%$ & - & - \\
\hline $\begin{array}{l}\text { Serum lactate clearance(in mmol/l) at the } \\
\text { end of 24hrs }\end{array}$ & $5.28 \pm 1.73$ & $1.19 \pm 1.75$ & $<0.0001^{* * *}$ & High \\
\hline \%lactate clearance at the end of 24hrs & $68 \%$ & $16 \%$ & - & - \\
\hline
\end{tabular}

Table 4: showing the correlation between serum lactate and veno-arterial carbon dioxide difference at T0,T6,T24

\begin{tabular}{|l|c|c|c|}
\hline Serum lactate and (v-a) co2 difference & 'r' Value & 'p' value & Significance \\
\hline At the time of admission (T0) & 0.67 & $<0.001^{* *}$ & High \\
\hline 6hrs after admission (T6) & 0.60 & $<0.001^{* *}$ & High \\
\hline 24hrs after admission (T24) & 0.33 & $<0.04^{*}$ & Significant \\
\hline
\end{tabular}

\section{Discussion}

Sepsis is a state of hypoperfusion. Low cardiac output leading to hypotension and decreased perfusion along with ineffective oxygen utilization occur in shock patients ${ }^{\mathbf{3}, 11}$. Central venous oxygen saturation, serum lactate are proven markers of tissue hypoperfusio. Recently veno-arterial carbon dioxide difference was proposed as an alternative marker of tissue hypoperfusion. Because septic shock is associated with higher mortality, it is important to study various markers which can predict the outcome in these patients.

We studied 60 septic shock patients and were divided into two groups based on the outcome as Survivors (26) and Non-survivors (34). venoarterial carbon dioxide difference and serum lactate was evaluated at regular intervals $(0 \mathrm{H}, 6 \mathrm{H}, 2 \mathrm{H}, 24 \mathrm{H})$ and were compared among both the groups.

In the present study, the demographic variables like age, sex, cause of the sepsis were similar in both Survivors and Non-Survivors.
Under physiological conditions, the venous carbon dioxide concentration is higher than in arterial blood due to $\mathrm{CO} 2$ production at the peripheral level, coupled with oxygen consumption and metabolism in general. Low flow conditions and non-anaerobic sources of the co2 output can increase the venous concentration and thus increment the normal difference ${ }^{12,13}$. The (v-a)co2 difference value is capable of indicating altered tissue perfusion in different clinical contexts, including sepsis ${ }^{13,14}$.

In the present study, The mean Veno-arterial carbon dioxide difference in Survivors at the time of admission (T0), 6 hours after admission (T6), 12 hours after admission (T12), 24 hours after admission (T24), was $7.23+1.41,5.8+0.87$, $5.71+0.80,5.52+0.82 \mathrm{mmHg}$ respectively and in Non-survivors was $8.51+1.31,9.4+0.88$, $9.84+1.01,9.78+0.78 \mathrm{mmHg}$ respectively with a statistically significant difference between survivors and Non-survivors.

The mean serum lactate in Survivors at the T0, 
T6, T12, T24 was 7.74 $\pm 1.54,5.70 \pm 1.29,3.9 \pm 1.18$, $2.45 \pm 1.09 \mathrm{mmol} / \mathrm{l}$ respectively and in Nonsurvivors was $8.69 \pm 2.08,9.09 \pm 1.58,8.94 \pm 1.34$, $8.79 \pm 1.33 \mathrm{mmol} / \mathrm{l}$ respectively. There was no significant statistical difference at the time of admission $\mathrm{T} 0(\mathrm{p}>0.05)$, and a statistically significant difference was observed at T6, T12, $\mathrm{T} 24(\mathrm{p}<0.05)$. The lactate clearance at the end of 6hours in survivors and non-survivors was $26 \%$ and $11 \%$, and at the end of 24 hours was $68 \%$ and $16 \%$, respectively.

A positive correlation is also observed between lactate and veno-arterial carbon dioxide difference, i.e., with an increase in veno-arterial carbon dioxide difference, an increase in serum lactate, and vice-versa was observed.

Ospina-Tascón GA et al. ${ }^{15}$ in, their study of venoarterial carbon dioxide difference in septic shock, concluded that persistently high or increasing veno-arterial carbon dioxide is associated with poor outcomes in septic shock and decreasing or persistently normal ( $\mathrm{v}-\mathrm{a}) \mathrm{co} 2$ difference is associated with better outcomes. Our study is in agreement with this study as the non-survivors had higher v-a co2difference $(9.78 \pm 0.78 \mathrm{~mm} \mathrm{Hg})$ and non-survivors had lower v-a co2difference at T6 p $<0.0001$.

In their study of prognostic value of venous-toarterial carbon dioxide difference during early resuscitation of patients with septic shock, Helmy TA et al. ${ }^{16}$ and compared venous-to-arterial carbon dioxide difference with that of lactate clearance and concluded that At T0, non survivors showed high PCO2 gap $(8.37 \pm 1.36 \mathrm{mmHg})$ than survivors $(7.55 \pm 0.95 \mathrm{mmHg})$ with $(\mathrm{P}=0.030)$. At T6, showed higher PCO2 gap $(9.48 \pm 1.47 \mathrm{mmHg})$ with $(\mathrm{P}<0.001)$ and higher mean lactate values $(62.71 \pm 23.66 \mathrm{mg} / \mathrm{dl})$ with statistically significant difference $(\mathrm{P}<0.001)$ than survivors where $\mathrm{PCO} 2$ gap and mean lactate values became much lower, $5.91 \pm 1.12 \mathrm{mmHg}$ and $33.61 \pm 5.80 \mathrm{mg} / \mathrm{dl}$, respectively. Survivors showed higher lactate clearance $(25.42 \pm 6.79 \%)$ with a statistically significant difference $(\mathrm{P}<0.001)$ than nonsurvivors $(-69.40-15.46 \%)$.
Our study showed similar results; the T0 venoarterial co2 difference was $7.23 \pm 1.41 \mathrm{~mm} \mathrm{Hg}$ vs. $8.51 \pm 1.31 \mathrm{~mm} \mathrm{Hg}$ in survivors and non-survivors $\mathrm{p}=0.0002$ and at $\mathrm{T} 65.8 \pm 0.87 \mathrm{~mm} \mathrm{HgVs}$ $9.4 \pm 0.88 \mathrm{~mm} \mathrm{Hg}$.serum lactate clearance also showed similar results with $\mathrm{p}<0.0001$. The positive correlation between the two metabolic parameters( lactate and veno-arterial carbon dioxide difference) was similar between the two studies. In addition, a higher veno-arterial carbon dioxide difference was observed at T12 and T24 in our study.

Results of the current study were closely similar to a prospective observational study done by Philippe Marty et al. ${ }^{\mathbf{1 2}}$ in 94 hospitalized patients in the ICU for severe sepsis or septic shock. The results of their study showed that there was a significant difference between $\mathrm{HO}$ lactate value and H6, H12, or H24 lactate value in the survivor group $(\mathrm{P}<0.05)$. Mean blood lactate concentrations were lower in survivors than in non-survivors patients at $\mathrm{H} 0(5 \pm 3.1 \mathrm{mmol} / \mathrm{L}$ vs. $6.9 \pm 4.3 \mathrm{mmol} ; \mathrm{P}=0.049$ ). Afterward, blood lactate concentrations were lower in survivors than in non-survivors at each studied time $(4.1 \pm 3.2$ vs. $6.9 \pm 4.3$ at $\mathrm{H} 6 ; 3.6 \pm 2.9$ vs. $6.7 \pm 4$ at $\mathrm{H} 12$ and $3 \pm 3$ vs. $6.4 \pm 4.5$ at $\mathrm{H} 24$. $\mathrm{P}<0.05$ for each studied period).

Our study also showed similar results with $(5.70 \pm$ $1.29 \mathrm{mmol} / \mathrm{l} . \mathrm{vs} \quad 9.09 \pm 1.58 \mathrm{mmo} / \mathrm{l}$ at $\mathrm{T} 6$, $3.9 \pm 1.18 \mathrm{mmol} / 1$. vs $8.94 \pm 1.34 \mathrm{mmo} / \mathrm{l}$ at $\mathrm{T} 12$ and $2.45 \pm 1.09 \mathrm{mmol} / \mathrm{l}$.vs $8.79 \pm 1.33 \mathrm{mmo} / \mathrm{l}$ in survivors and nonsurvivors with $\mathrm{p}<0.0001$

Mahajan $R K$ et al. ${ }^{16}$ studied patterns of scvo2 lactate and ( $\mathrm{v}-\mathrm{a}) \mathrm{co} 2$ difference in the prognosis of septic shock patients and concluded that in septic patients, baseline $\mathrm{vaCO}_{2}$ of $\leq 6 \mathrm{mmHg}$ was associated with higher mortality, but only in those patients with $\mathrm{ScvO}_{2}>70 \%$. This was thought to be due to impaired mitochondrial respiration in sepsis with nonutilization of oxygen by the cell may decrease $\mathrm{CO}_{2}$ production, since anaerobic metabolism is less efficient in producing $\mathrm{CO}_{2}{ }^{\mathbf{5 7 , 5 8}}$. Our study is in disagreement with this study, as in our study, higher initial ( $\mathrm{v}-\mathrm{a}) \mathrm{co} 2$ difference 
$(8.51 \pm 1.31 \mathrm{~mm} \quad \mathrm{Hg})$ was associated with mortality.

The current study showed that (v-a)co2 at T6,T12,T24 showed higher sensitivity and specificity in predicting mortality in patients with septic shock.

The importance of identifying patients at high risk of dying of septic injury, through the determination of veno-arterial carbon dioxide difference, would recognize patients who may require more complex interventions to reduce mortality.

A longer study period and a higher sample size would have yielded better results.. Continuous monitoring of the these parameters instead of measuring at regular intervals and measuring changes with interventions would have been more relevant to improvise the present study. But this could not be done due to technical and cost constraints. Other factors that influence Carbon dioxide production, like and alveolar ventilation and diet, were not addressed.

There is a scope for further study to know the mitochondrial function impairment, study of various biomarkers associated with hypoperfusion in septic shock patients.

\section{Summary}

In the present study,60 adult patients, aged between 18-80 years of either sex who were admitted into ICU who satisfied the criteria of septic shock (according to third consensus definition,2015) were included.

After getting approval from the institutional ethics committee, and written informed consent from patients/patient's attendants, intraarterial (radial or femoral) and central venous catheter (internal jugular or subclavian) were secured, and all patients were treated according to surviving sepsis guidelines 2016.

Serum lactate and, veno-arterial carbondioxide difference were recorded from the central venous and arterial blood samples on admission(T0) and at 6hrs (T6),12 hrs(T12),24 hrs(T24) postadmission. Data was entered on the pre-designed case proforma, and results were analyzed. Patients were followed up until death or hospital discharge for a period of 28 days and were categorized into survivors and non-survivors. There were 26 survivors and 34 Non-survivors. Patterns of these parameters during the first 24 hours were observed. The correlation between parameters and to the outcome was analyzed statistically.

Demographic variables were comparable in both the groups.

Veno-arterial carbon dioxide difference initially and at later stages showed a significant difference between Survivors and Non-survivors.

A positive correlation was also observed between serum lactate and Veno-arterial carbon dioxide difference in both the groups.

Initial lactate measurement showed no difference between Survivors and Non-survivors. Serial lactate measurements at T6, T12, and T24 showed a significant difference between Survivors and Non-survivors with a highly significant and sensitive difference at T6. Low lactate clearance was observed in non-survivors.

\section{Conclusion}

In septic shock, high Veno-arterial carbon dioxide difference initially and at 6hours, 12hours, and 24hours is associated with mortality. It is an independent predictor of mortality. Increased lactate clearance at 6hours and 24hours is associated with improved survival. Low lactate clearance is associated with mortality. There is also a positive correlation between Veno-arterial carbon dioxide difference and Serum lactate.

\section{References}

1. Singer M, Deutschman CS, Seymour CW et al (2016) The Third Inter- national Consensus Definitions for Sepsis and Septic Shock (Sepsis- 3). JAMA 315(8):801-810.

2. Kumar, V.; Abbas, A.K.; Fausto, N.; et al., eds. (2007). Robbins Basic Pathology (8th ed.). Saunders, Elsevier. pp. 102-3. 
3. Ince $\mathrm{C}$, Sinaasappel $\mathrm{M}$, et al., Microcirculatory oxygenation and shunting in sepsis and shock.Crit Care Med 1999; July 27(7):1369-77.

4. Hollenberg SM. Think locally: Evaluation of the microcirculation in sepsis. Intensive Care Med. 2010;36:1807-9.

5. Trzeciak S, Rivers EP. Clinical manifestations of disordered microcirculatory perfusion in severe sepsis. Crit Care. 2005;9(Suppl 4):S20-6.

6. Palizas F, Dubin A, Regueira T, Bruhn A, Knobel E, Lazzeri S, et al. Gastric tonometry versus cardiac index as resuscitation goals in septic shock: A multicenter, randomized, controlled trial. Crit Care. 2009;13:R44.

7. Rivers E, Nguyen B, Havstad S, Ressler J, Muzzin A, Knoblich B, et al. Early goal-directed therapy in the treatment of severe sepsis and septic shock. N Engl J Med. 2001;345:1368-77

8. Dellinger RP, Levy MM, Rhodes A, Annane D, Gerlach H, Opal SM, et al. Surviving sepsis campaign: International guidelines for management of severe sepsis and septic shock: 2012. Crit Care Med. 2013;41:580-637.

9. Mesquida J, Borrat X, Lorente JA, Masip J, Baigorri F. Objectives of hemodynamic resuscitation. Med

Intensiva. 2011;35:499-508

10. Ospina-Tascón GA, Bautista-Rincón DF, Umaña M, Tafur JD, Gutiérrez A, García $\mathrm{AF}$, et al. Persistently high venous-toarterial carbon dioxide differences during early resuscitation are associated with poor outcomes in septic shock. Crit Care. 2013; 17:R294
11. Hollenberg SM, Ahrens TS, Annane D, Astiz ME, Chalfin DB, Dasta JF, Heard SO, Martin C, Napolitano LM, Susla GM. et al.Practice parameters for hemodynamic support of sepsis in adult patients: 2004 update. Crit Care Med. 2004;32:19281948

12. Marty P, Roquilly A, Vallée F, et al. Lactate clearance for death prediction in severe sepsis or septic shock patients during the first 24 hours in Intensive Care Unit: an observational study. Ann Intensive Care. 2013;3(1):3.

13. J.Mallat, B.Vallet.Difference in venousarterial carbon dioxide in septic shock. Minerva Anestesiol, 81 (2015), pp. 419425.

14. L. Lind.Veno-arterial carbon dioxide and $\mathrm{pH}$ gradients and survival in critical illness.Eur J Clin Invest, 25 (1995), pp. 201-205.

15. Ospina-Tascón GA, Bautista-Rincón DF, Umaña $\mathrm{M}$, et al. Persistently high venousto-arterial carbon dioxide differences during early resuscitation are associated with poor outcomes in septic shock. Crit Care. 2013;17(6):R294.

16. Helmy TA, El-Reweny EM, Ghazy FG.et al.Prognostic Value of Venous to Arterial Carbon Dioxide Difference during Early Resuscitation in Critically Ill Patients with Septic Shock.Indian J Crit Care Med. 2017 Sep;21(9):589-593. 